\title{
Exploring Malaysian University Language Teachers' Experiences with Research Publications: a Phenomenological Inquiry
}

\author{
Sarala Thulasi Palpanadan, PhD \\ Centre for Language Studies \\ Universiti Tun Hussein Onn Malaysia \\ Nurulisyazila Binti Othaman \\ Centre for Language Studies \\ Universiti Tun Hussein Onn Malaysia \\ Iqbal Ahmad, PhD \\ Faculty of Education, \\ University of Malakand \\ Pakistan
}

\begin{abstract}
The contemporary university educators work in a competitive environment and are under pressure for several reasons including having to expand their own research and publication capacities. Few studies have addressed the language teachers' research publications issues in the context of Malaysian universities. The purpose of this study was to explore the extent of research involvement and its impact towards the experience of research publication among the Malaysian university language teachers. Thus, a qualitative phenomenological inquiry approach was employed where semi-structured interviews were conducted with 10 language teachers at a university in Malaysia. A thematic analysis was carried out which revealed five themes related to the research publication issues: improving practice, funding, motivation, collaboration, and recognition. This study recommended that the university language teachers needed practical orientation, financial support and encouragement to better address the arising matters and facilitate the delivery of high quality research publications.
\end{abstract}

Keywords: research publications, phenomenological inquiry, university language teachers, improving practice

\subsection{Introduction}

Nowadays, research involvement has gained its popularity in various higher institutions, especially universities. The world has seen various changes taking place in the policies of universities where research involvement is becoming more and more of a priority (Findlow, 2012; Tran, Burns \& Ollerhead, 2017). Research involvement refers to the activities related to studies conducted scientifically and shared with others with a meaningful purpose. These sharing can be communicated orally or in written form. Oral communication can be done via conference, academic talks and seminars. Meanwhile, written discourse can be done in terms of publication such as books, journal articles, newspapers, and proceeding. Therefore, researchers are able to contribute to the current body of knowledge through activities related to studies conducted scientifically and shared with others via speech or written form.

The contemporary university educators work in a competitive environment and are under pressure for several reasons including having to expand their own research capacities. Research and publication have become important criteria in the ranking of the universities globally (Azmi, 2006). Even within the country of Malaysia, universities are ranked based on their staff's achievements in many areas especially in research and publication. In Malaysia, research involvement is encouraged by the Ministry of Education(MOE) not only in higher learning institutions but also among school teachers where innovative teaching and learning approach is emphasized (MOE, 2013; Economy Planning Unit, 2015). This can be done by carrying out studies such as action research from time to time to test new strategies or approaches in the classrooms analytically and recording them accordingly. 
Therefore, research involvement has become an important part of the lives of the academicians these days. In the context of Malaysian universities, academicians are referred to the educators with and without a Philosophy of Doctorate $(\mathrm{PhD})$ degree. Those with a $\mathrm{PhD}$ degree would have undergone a vast research experience while pursuing their studies and become familiar with the research conventions. Meanwhile, those who are yet to pursue $\mathrm{PhD}$ might face some challenges pertaining to research even though they are exposed to research during their first and second degree studies. This study explores the challenges of the language teachers in relation to research and publication issues. These educators, known as language teachers, chose to focus more on teaching over research and publication with regards to their career. It is important to study the performance and perceptions of these language teachers in terms of their capacity in research involvement as they encompass a huge portion of the academic staff of a particular department in UTHM. Therefore, their capacities in publication and research activities would contribute significantly to the overall achievement of the university.

\subsection{Literature Review}

Basically, research related work is given the utmost importance in higher learning institutions (Boud \& Brew, 2013). However, the university academicians find the research involvement as a challenging task (Izah\& Nor Mazlina, 2009). In this situation, the staff is not able to retreat from getting involved in the research related activities such as presenting papers in conferences and seminars. In addition, their works need to be published as well such as in journals, newspapers or proceedings to add to the current body of knowledge in their respective fields. Apart from that, the academic staff is also encouraged to be involved in the public services such as giving academic talk, facilitating students' academic activities and providing social services to the working adults to promote life-long learning attitude among them. Therefore, research work involving publication, presentation and social service can be demanding to the educators apart from their core business, which is teaching where it also demands a lot of attention in terms of $21^{\text {st }}$ century classroom and online learning methods.

In the past, lecturers and teachers were mainly focused on teaching and learning activities (Sterner, 1999). Their devotion was very much classroom oriented in preparing students to obtain good grades in the various types of assessments such as examination, coursework and projects. Hence, the educators gained popularity on basis of their ability in imparting the subject and content knowledge to their students effectively. However, there is a huge paradigm shift now where educators are also evaluated in terms of their research involvement. The higher, the position of the teacher or lecturer, the higher the level of the journal publication that is required of them to be published based on the respective journals' impact factors. In this study, the language teachers in the selected university are expected to publish their work at least at non Scopus level. Even then, the language teachers seem to struggle in getting their task done. Many research is conducted on the challenges faced by the lecturers but few focused on the area of the language teachers who have not undergone the actual process of conducting research on a bigger scale as how a $\mathrm{PhD}$ student might have gone through in the process of completing their research. Therefore, this research is important and timely to address the challenges and trauma that the language teachers, in particular, are going though.

The emphasis on research activities has raised multiple responses from various groups of academician from various parts of the world. Archer's (2008) highlighted the importance of financial aid in encouraging research where the lecturers aided with financial support found it enjoyable to do research and the lecturers without financial aid were unenthusiastic to be involved in research. It is understood that some papers or articles are charged to be published and the charges are not cheap. Even though there are some free journals, normally, the 'queue' is too long that these lecturers dread waiting. And by the time, their papers get published; it would be over their assessment period of time for their annual performance evaluation, unfortunately. Therefore, they might miss out the current year's publication quota which can be a stressful duration for them. A study conducted by Sanmugam \& Rajanthran, (2014) regarding the polytechnic lecturers' perceptions towards research showed that many lecturers prefer to participate in internal and zone level seminars. This is mainly because it is free of charge and thus, it is very convenient for them to accomplish the criteria of paper presentations and publications to meet the institutional targets.

As a matter of fact, the culture of prioritizing research involvement is slowly taking place. Apparently, educators realize the importance of conducting research in academia as they realize its significance towards their work advancement and to follow up with the development of the current needs of teaching and learning process (Bai \& Millwater, 2011; Hiep, 2006). 
However, many educators still succumb to their teaching workload. They find difficulties in allocating time to be involved in research works as they have other priorities such classroom preparations, test papers to mark and courses to attend. These are the common scenario of educators in higher institutions and schools. Hence, research work takes the last place in their urgency list.

Mendoza (2008) stated that the educators' competencies including the ability to apply research tools appropriately and speed in carrying out the research are among the important factors in making sure a research can be carried out successfully. Hence, the educators' knowledge in terms of statistical application and research procedures are crucial parts in research. Lack of knowledge regarding the research conventions can also impede the research activities which can lead to dissuasion among educators. In addition, Iza and NorMazlina (2009) highlighted that appropriate writing skills are crucial for educators to be involved in research work especially in getting a paper published. Therefore, there are many factors that have to synchronize before a research can be completed. All these take, effort and motivation.

Some studies were also conducted to investigate the academicians' emotional effects towards publication. The educators seemed to have different types of feelings towards their capabilities in publishing papers (Leathwood \& Read, 2013; Xu, 2014). Those who were not able to publish were found to have suffered from frustration while those who managed to publish seemed to have enjoyed the research activities. Archer (2008) stated that these educators had to struggle to find various help such as finding new approaches that could create path for them to publish and financial support in order to survive in their respective institutions. Thus, the incapacitated educators may face mental stress due to low publication capacities.

In higher leaning institutes, the experience in research and publication plays a crucial role where the experienced lecturers may find it manageable to do research while the inexperienced lecturers struggle to get their work published. This scenario is even more serious among the language teachers who are considered inexperienced as far as research and publication are concerned. They seemed to be grappling with research in terms of the research conventions. In this study, the language teachers' research involvement was studied and their perception towards research involvement was explored to identify their needs to enhance their participation in this discipline besides upgrading their publication capacities. All university educators in Malaysia are encouraged to do research and publication. However, many educators especially the language teachers seem to struggle to get them involved in the research work. This study explores the involvement of the language in research activities.

\subsection{Research Objectives}

This study aims to achieve the following research objectives:

- To explore the extent of research involvement among the language teachers in the university.

- To investigate the impact of research involvement among the language teachers in the universities.

\subsection{Methodology}

\section{3.1 Design and Procedures}

This qualitative research study was conducted using a transcendental phenomenological approach. This approach presents a description of meaning of the lived experiences of many individuals about a phenomenon. In this study, we provided the descriptions of the language teachers' experiences about research involvement and the barriers they face during the publication process. The main aim was to describe the commonalities of experiences on research publications. Through this study, we try to generate essence based on the descriptions of their lived experiences. The study was founded on the positivist paradigm that uses a more scientific approach to research. Under this method several steps were used to conduct the study and to inquire into the perspective of the research participants based on in-depth and robust data collection and analysis. In this study, a lengthy and logical process was applied to validate the instrument and check its reliability and to conduct the study based on the belief system.

\subsection{Sampling of Participants}

In this study, a homogenous group of language teachers were identified and recruited for interviews as sample. A sample of 10language teachers took part in the study. There is no standard for minimum number of research participants in qualitative research because the main aim is not to generalize the results of the study. The selection depends on the availability of new information till the saturation point occurs in the data (Yin, 2004). Besides, further participants were not recruited after the saturation point was reached when further no new information was identified. The experience of all the participants ranged from 5 to 15 years. 
These participants shared their experiences of research publications as the department members. Written consent was obtained from the participants and they were assigned with pseudonyms.

\subsection{Data Collection}

Before beginning data collection, the researchers bracketed biases to ensure data accuracy. Data were collected using a semi-structured interview protocol. The instrument was developed and reviewed by three qualitative experts. The instrument was edited and refined based on their feedbacks. The interviews were conducted with the language teachers and recorded in the form of narrated notes. The researchers prepared the open-ended questions by referring to the needs analysis model established by Munby (1978). The model was called the 'Communication Needs Processor' or CNP. The interview protocol included 11 questions which were adapted from the CNP model covering the following topics: research publications, purpose of research publication, supportive environment, capacity enhancement for publications, challenges faced during publications, and suggestions for quality publications.

During the interview process, several probes were asked as follow up questions to the main questions. The participants were encouraged to elaborate their views and clarify their responses during the interview process. Some specific questions were also asked to develop themes during the interviews. All the interviews were conducted by the first author. Verbatim transcripts of the interviews were generated and kept immediately after each interview. The language teachers were also asked to complete reflections on the interview questions related to their experiences of research publications after the interview sessions. Data collection was completed and ended based on saturation point when no further themes and information emerged to add in order to further understand the phenomenon.

\subsection{Instrument Validation}

The instrument used in this study was validated for reliability and validity purposes. The reliability techniques such as recording of field notes thorough narrative forms, member checking and recording interview through audiotape were used to ensure the general accuracy of the findings. Apparently, no major discrepancy was found. Thus, themes were generated. Some of the validation techniques used in this study included bracketing for clarification of bias, taking narrative notes and member checking. The possibility of repetitions and redundancy of data were controlled through member checking. This helped in maintaining the credibility of the information and findings as well as the interpretations of the results. Subsequently, five major themes were identified which were mailed to the participants for their review. They examined the themes and reflected on the accuracy of the themes. They confirmed that the themes reflected their perspectives and experiences.

\subsection{Data Analysis}

In this study, the structured method of inductive data analysis was used (Kerse et al, 2004). All the transcripts were checked and read sequentially. The memos were recorded for identifying and highlighting the key concepts. The following steps were undertaken for immersing the data. Firstly, horizontalization was done where equal value and importance to each statement were given. Data was also coded and labeled descriptively. Secondly, several irrelevant statements were eliminated and data were reduced to determine the main constituents of the participants' experiences. Groups of related constituents were clustered together and the categories were labeled thematically. In this way, numerous categories of invariant constituent of the language teachers' experiences were identified. This step was repeated several times and finally, five themes related to the experience of the language teachers emerged. The themes were checked and reread to verify that they were explicitly expressed. The compatibility of the five themes with the words of the participants were also checked. Subsequently, the identified themes were utilized to develop textural and structural descriptions of the essence of the language teachers' experiences.

\subsection{Results}

Five themes emerged based on the interviews with the language teachers: improve practice, funding, motivation, collaboration, and recognition. The major quotes which represented the perspectives of the participants are illustrated in Table 1. All names are pseudonyms (for the purpose of protecting the identity of the participants).

\subsubsection{Improve Practice}

The participants expressed that relevant knowledge of publications was important to write research papers. They highlighted that they needed further opportunity to produce quality research publications. 
Some of them believed that through research work they could share findings with others that played a key role in improving their writing practices.

One teacher remarked, "I produce research publication that helps me to achieve Key Performance Index (KPI) in my job. I learnto carry out new teaching techniques or methods and see whether they give impacts or not".

The participants expressed that research publication provided wider opportunities to evaluate teaching and learning practices. Two participants added that writing practices enabled them to find out their weaknesses and strengths that led to the improvement of teaching and learning practices. All the participants expressed that they applied the findings of their research publications in solving their academic problems.

During the interview one of the participants indicated that, "I write papers and I apply the new learning based on my learning to improve my practice. You know ... I evaluate my practice and use the new knowledge in evaluating my teaching practice".

Majority of the participants strongly believed that writing research papers was essential for them to improve their professional practices. They stated that their job performance was also related to research publications. Furthermore, they highlighted that they needed to apply the new learning in their classes based on publications. However, they mentioned that they needed further encouragement and support in the area of publication. They were also found to expect some guidance and support from the university in terms of providing some effective ways to solve their problems in research publication.

\subsubsection{Funding}

The participants experienced the constraints of funding issues in terms of carrying out research and publications. There was some funding for certain projects, but it was not sufficient to support publication practices throughout the service. Due to the lack of financial support the participants could not go for publications in Scopus and other high quality journals. They highlighted that many publishers demanded fee for publishing papers which they could not afford to make research publication a habit in the long run.

One participant expressed that, "I want to publish papers but due to the financial cost involved I cannot...hmmm ... you know sometimes it becomes very difficult to publish".

Most of the participants suggested that the availability of funds for publication is an opportunity for them to get their research published in different journals. For this purpose, there is a need to allocate a sizable amount of funds for the purpose of publications since quality publication also adds to the ranking of the university. However, during the interview many participants referred to availability of funding issue for research publications.

Another participant shared that "I have experienced that some journals demand high fee for research work publications... I believe that if there is a financial support, this need would be met and faculty members would be able to publish their works in different journals.

Apparently, majority of the participants viewed publication demanded high fee, therefore, they find it difficult to publish in journals. Few participants mentioned they could publish at their own expenses. Most of them suggested that there is a need for sufficient budget for publications. This will help the faculty members to publish their research work in high quality journals. In view of all teachers, publication was an important need for their academic development but sometimes lack of financial support did not allow them to go for research publications.

\subsubsection{Motivation}

All participants believed that motivation was an important factor in research publications. Some participants stated that when there were some kinds of reward attached with publications, they would be more inclined to produce the research papers. However, this situation was grim in their current scenario. One teacher highlighted, "you know...hmm... I have observed that many language teachers do not have exposure to research. So, they are not very much interested in producing research publications."

Some participants expressed the importance of providing rewards to the language teachers upon producing a research work. This would increase their motivation to do further involve in research publications. They considered exposure and training to be highly important for quality production. Another participant stated, "I think if the language teachers participate in seminars and research conferences, they would get more expertise and knowledge about research publications. There is a need to give more importance to these aspects ... I believe that I can do better research work if I find more opportunities to participate in more national and international conferences, however, I find that the main focus is on coverage of module rather than producing research work." 
Some participants shared that there were less opportunities to interact with experts in the field of language research. The participants unanimously stressed on the need of providing motivation to faculty members to be involved in real research and development situations for them to do better in future. Thus, it is essential to provide the language teachers with abundance of opportunities to do their research work.

Some participants shared that the language teachers believed that publication was an important topic to focus on as it also contributed towards ranking of university and individual development of its academic staff. They felt that there must be a supportive environment and research culture in the university to promote research efforts of the faculty or department members. Although the language teachers widely expressed that research publications played a key role in the professional development of university language teachers, there should be proper incentives for the research publications for every individual. In this way they would dedicate more time and efforts for research publications.

\subsubsection{Collaboration}

The participants expressed that collaboration was the key for quality research. However, they found it difficult to find time be involved in research publications as they were mostly engaged in the course coverage. They stated that they needed to cover the specified course within a certain period of time. Hence, they found it difficult to allocate time for research publications. One of the participants described that, "it is quite challenging to focus research in the absence of research collaborations... when you are required to allocate most of your available time to cover the given course syllabus. You know it is very difficult... research is a demanding and full time activity... you cannot do it so easily."

Some participants said that they found it difficult to locate journals in the specified language area or other quality publication. Through collaborations with other universities this could be resolved. They further explained that searching for journals is a time consuming activity. Thus, they found it challenging to find the right journals for publications. Hence, they preferred to give their attention towards course coverage rather than research publications. Besides, some participants complained about other activities which demanded their time as well where one participant mentioned, "I find it difficult to produce papers in midst of other course related activities and seminars that I have to attend as part of my job...If you do not go, you need to justify it... hmm... so it is important and this takes a lot of time which you can spend to write papers."

Resources and budget were also barriers to materialize collaboration. The teachers believed that lack of financial support was one of the biggest challenges in research publications. Some participants argued that due to involvement in course teaching it was very challenging to give attention towards publications. In addition, one participant highlighted, "I try to focus on publication by collaborating with others, but you know, sometimes, I am in the classroom most of the time, so I need to evaluate and examine students, need to check assignments and so on... in this way I cannot find much time to write papers... hence I am blocked.... I want to have more flexible time to collaborate with other researchers."

Generally, most of time, the focus of the participants seemed to be moreon teaching rather than research work. All the participants seemed to agree to the fact that writing research papers was a technical academic activity that needed expertise in writing. They suggested that there should be some trainings and orientations on research involvements so that they could improve their writing skills in producing quality research publications. They said training and orientation would have positive impact on their writing skills which was one of the main hurdles to produce quality papers. Therefore, collaboration with other experienced researchers was highlighted as an important factor. Another participant further highlighted this situation in the following words, "I think because I am so excited to produce quality publication, however, I feel I have to improve my writing skills, this is one of the main reasons I have to do., I need exposure and training in writing quality papers."

Many participants suggested that due to the lack of support and exposure to publications, the language teachers were unable to publish sufficiently. Nonetheless, the participants showed a positive attitude towards the idea of working together as a team and group as far as research publication is concerned. Majority of them suggested for collective work in publications and seemed more inclined to to create an environment of a shared research culture.

\subsubsection{Recognition}

Basically, recognition of research efforts was found to be an encouraging element which could propel the participants towards getting involved in research work. 
They believed that work recognition had a positive impact on the performance. One of the teachers stated, "If your efforts are appreciated and recognized ... you go for more quality efforts... research is a challenging task."

The participants believed that recognizing their research work in different ways by giving certificates and prizes as well as reducing the teaching hours might encourage them to do better in research publications. Some of them stated that appreciation and recognition shall give them feeling of value and importance which will culminate in more research pursuits. One of the participants expressed that, "I think, you know you feel good and encouraged when someone praises your efforts and gives it value...or maybe by reducing the workload of teaching."

Majority of the teachers suggested that there should be some form of appreciation and recognition for their research efforts. One participant stated, "I think there should be some kind of plan to reduce workload burden on teachers and provide them more time to work on publications. I mean more opportunities for research work... this will increase their attention towards research publication."

Time and resources should be provided to them so that they could initiate research work and publications and overcome the barriers which will maximize opportunities for research publications. The participants also suggested that there should be more suitable grants for research publications and high incentives to divert their attention towards research publications. Apparently, all participants recognized that recognition improves performance as they get appreciation for their little efforts.

\subsection{Discussion}

This study explored the research publication issues among the language teachers of a particular department in a university in Malaysia in the context of phenomenology. It provides an in-depth and holistic understanding of the experiences and perspectives of language teachers related to research publications. The language teachers expressed that they realized conducting research and producing publications are important but they did face some challenges in research publications. In the context of this study, five themes (improving practice, funding, motivation, collaboration and recognition) were explored in detail. This qualitative research has shown complex perspectives of the language teachers based on their own research publication experiences.

The first theme that emerged from this study was the language teachers' professional practice. They perceived that they found research publication is very expedient for improving their professional practice as classroom practitioners. Based on the research findings, they could adopt new methods which could challenge their previous tough practices. Thus, they could improve their practices as professionals. The language teachers also realized that opportunities of learning new practices had valuable implications for their students as well. Since this area of research has not been dealt well in the past in the context of language research, further research needs to be conducted to examine the impact of research publications on language teachers' role as classroom practitioner and its impact on students' learning.

Next, the language teachers' research publication was influenced by motivation factor. This study found that when teachers get motivated they take interest in research publications. Although, the language teachers did not express confidence about their current interest in research publications, they suggested that there should be some kind of motivation for them that could improve their perception and interest in this discipline. This could be done through rewards and other incentives. Other than that, funding was also another emerged theme of the study. The language teachers found it difficult to obtain financial support as conducting research and getting them published incur a lot of monetary issues. They mentioned that with their little experience in research area, it is difficult to getting funding or apply any grants as they would have to compete with the other experienced professionals in getting financial support such as grants. Moreover, publications do not come cheap and carrying out research also requires money in terms of supporting their transportation, printing and souvenirs for the participants if relevant. Therefore, the language teachers were worried that they would not be able to incur all the expenses for small scale research let alone conducting research on a bigger scale.

This study discovered that collaboration was an important factor that influenced the language teachers' intention for research publications. They suggested unanimously that there should be closer collaborations within the country to and between various institutes around the world to carry out research in language area. This provides wider opportunities to develop associations in order to promote research publications on a bigger scale. Last but not least, recognition was another major finding of this study. The language teachers expressed that appreciation and encouragement was an important element in the process of research publication and its development. 
This was a significant theme that emerged from the data of this study. When people get appreciated for their contributions, their performance would be improved and their activities would speed up.

\subsection{Conclusion}

This study highlighted that the language teachers needed support in many ways to be involved in research publications. The language teachers needed help to improve their professional practices in terms of conducting research and publish papers. The study further highlighted that there was a lack of funding for research publications. The language teachers required financial support to carry out research and publish especially with other quality publishers. The study identified that when the language teachers were motivated they would take interest in research work and produce quality publications. There was also a need to increase the motivation level of language teachers in publications through various rewards, incentives and appreciations. For this purpose, their efforts should be recognized so that it would provide a positive impact on their behavior and attitude towards research publications.

Based on the results of this study, the following suggestions are forwarded:

- Helping language teachers by providing them training and orientation in research publications. This will help them improve their professional practices as teachers and researchers.

- Encourage language teachers through appreciation and rewards for their research work and efforts. This will strengthen their behavior and they will participate in quality language research publications.

- More funds are needed for language teachers to carry out quality publications. This will encourage them to do more research.

- The works of teachers need to be appreciated and recognized. This could be achieved by providing them a supportive and helping environment for research and development in language area.

- There is a need to develop links with other institutions and organizations for promoting a research culture in the university in which language teachers could participate.

- Future quantitative research need to be conducted for determining whether the perspectives shared in this study are also present in larger population.

In conclusion, the language teachers agreed that research involvement is very important for their carrier and would like to indulge more significantly if more opportunities are provided to them. The five factors identified in this small scale study can be considered for future research to be explored in depth to obtain a framework of the university educators' needs for research involvement.

\subsection{Table}

Table 1: Themes and Participants’Supporting Quotes

\begin{tabular}{|c|c|}
\hline Themes & Participants' Supporting Quotes \\
\hline $\begin{array}{l}\text { Improve } \\
\text { Practice }\end{array}$ & $\begin{array}{l}\text { - increase own knowledge } \\
\text { - share findings of experiment results for improvement } \\
\text { - share our own findings for improvement of practice } \\
\text { - for evaluation of practice } \\
\text { - teaching outcome improvement } \\
\text { - ways to improve teaching and learning } \\
\text { - to be applied in their classes } \\
\text { - to provide solutions or how to deal with problems } \\
- \text { apply findings and draw conclusions }\end{array}$ \\
\hline Funding & $\begin{array}{l}\text { - less supportive financially } \\
\text { - expensive due to lack of funding } \\
\text { - no grant for language teachers } \\
\text { - difficulties to publish in Scopus publication } \\
\text { - got interest but no financial aid } \\
\text { - budget issue for publication }\end{array}$ \\
\hline Motivation & $\begin{array}{l}\text { - lack of exposure to research } \\
\text { - less guidance } \\
\text { - doing module coverage not so interested in research } \\
\text { - less opportunity to work with experts } \\
\text { - need to motivate for publications } \\
\end{array}$ \\
\hline Collaboration & $\begin{array}{l}\text { - team members' cooperation/ commitment } \\
\text { - do not share knowledge' 'skills } \\
\text { - need guidance how to produce papers } \\
\text { - relevant professional development } \\
\text { - create collaborations between universities and others } \\
\text { - collaboration with other universities } \\
\end{array}$ \\
\hline Recognition & $\begin{array}{l}\text { - more training should be provided } \\
\text { - offer suitable rants to the staff } \\
\text { - provide courses that ate related to the research. } \\
\text { - incentives high point for promotions } \\
\text { - plan how to reduce the workload } \\
\text { - more opportunities should be given to involve in research }\end{array}$ \\
\hline
\end{tabular}

Sponsoring information - Acknowledgement: The funding for this publication was provided by UTHM Contract Grant (C065). 


\subsection{References}

Anh Tran, Anne Burns, Sue Ollerhead. (2017). ELT lecturers' experiences of a new research policy: Exploringemotion and academic identity.System. 67, 65-76.

Archer, L. (2008). The new neoliberal subjects? Young/er academics' constructions of professional identity. Journal of Education Policy, 23(3), 265-285.http://dx.doi.org/10.1080/02680930701754047.

Azmi, S. (2006).Attaining and maintaining world class university standards. Paper Presented at the Star-ACMS. Conference, Kuala Lumpur, Malaysia.

Bai, L., and J. Millwater, (2011). Chinese TEFL academics'perceptions about research: an institutional case study. Higher Education Research \&Development, Vol 30(2), 233-246.

Boud, D., \& Brew, A. (2013). Reconceptualising academic work as professional practice: Implications for academic development. International Journal for Academic Development, 18(3), 208-221.

http://dx.doi.or g/10.1080/1360 144X.2012.671771

Findlow, S. (2012). Higher education change and professional-academic identity in newly 'academic' disciplines: The case of nurse education. Higher Education,63(1), 117-133. http://dx.doi.org/10.1007/s10734-0119449-4.

Hiep, P. H. (2006). Researching the research culture in English language education in Vietnam. TESL-EJ, 10(2), 1-20. http://www.tesl-ej.org/ej38/a10.pdf.

IzahMohd Tahir and NorMazlina Abu Bakar (2009). An Evaluation of Lecturers Perceptions Towards Research.The Social Sciences, 4(5), 416-423.

KementerianPendidikan Malaysia - MOE. (2013). Pelan Pembangunan Pendidikan Malaysia 2013-2025. Kuala Lumpur, Percetakan Nasional Berhad.

Kerse, N., Thomas, D. R., Neuwelt, P., Crampton, P., Dixon, R., Dyall, L., et al. (2004) Consumers' views and experiences of primary health care in New Zealand: A snapshot. Wellington, New Zealand: Ministry of Health.

Leathwood, C., \& Read, B. (2013). Research policy and academic performativity: Compliance, contestation and complicity. Studies in Higher Education, 38(8),1162-1174. http://dx.doi.org/1 0.1080/0307 5079.2013.833025.

Mendoza, R. R. (2008). Research Competencies and Interests of Accounting Educators in the Philippines. http://ssrn.com/abstract=1831240 or http://dx.doi.org/10.2139/ssrn.1831240

Munby, J. (1978). Communicative syllabus design. London Cambridge University Press. Ninth Malaysia Plan , 2006-2020.

Mourtaga, K. (2004). Investigating Writing Problems among Palestinian Students: Studying English as a Foreign Language, Bloomington, Indiana. Uthor House.

Sanmugam, S.T. \&Rajanthran, N. (2014). Exploring Malaysian Polytechnic Lecturers' Perceptions towards Research: An Institutional Case Study. Procedia - Social and BehavioralSciences. 123, 398 - 405.

Sterner, A., (1999).Faculty attitudes towards involvement in grant-related activities at

Predominantly Undergraduate Institution (PUI). SRA J., 31(1), 5-21.

Unit PerancangEkonomi - EPU. (2015). KertasStrategi 21: Inovasi Pemacu Kejayaan. Putrajaya. Jabatan P erdanaMe nteri.

$\mathrm{Xu}$, Y. (2014). Becoming researchers: A narrative study of Chinese university EFL teachers' research practice and their professional identity construction. Language Teaching Research, 18(2), 242-259. http://dx.doi.org/10.1177/1362168813505943

Yin, R. K. (2003).Case study research: Design and methods ( $3^{\text {rd }}$ Eds.). Thousand Oaks, CA: Sage. 